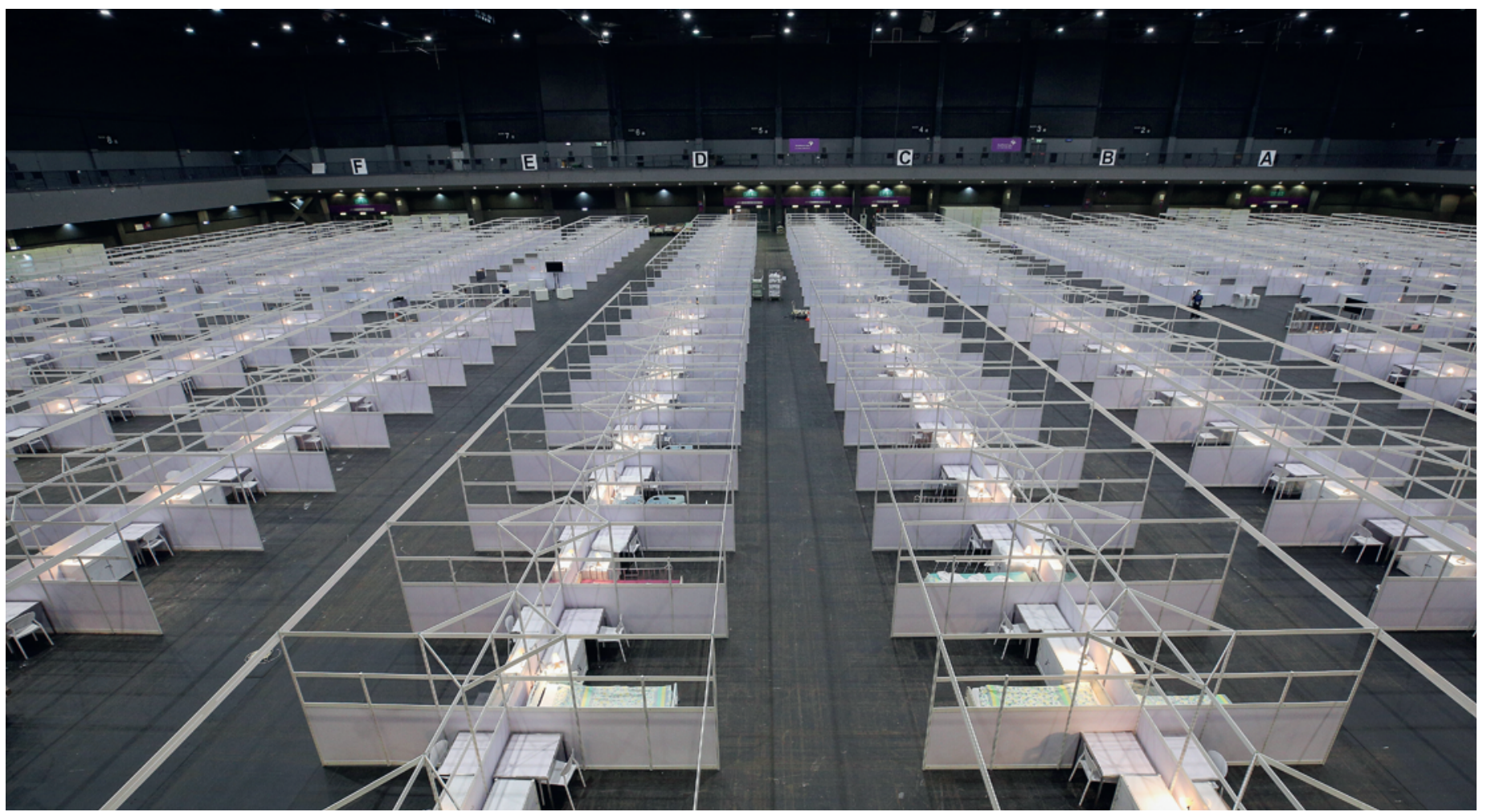

Les halles du centre des congrès Asia World Expo, transformées en hôpital temporaire pour les cas de Covid-19 ne nécessitant pas d'intervention médicale. (c) Autorité hospitalière de Hong Kong

\title{
Comment Hong Kong a maîtrisé le virus
}

\section{Julie Zaugg}

Journaliste freelance

La cité portuaire est largement parvenue à se défaire du Covid-19, grâce à un cocktail de mesures radicales élaborées dans le sillage de la pandémie de SARS. Mais la population y a laissé une partie de ses libertés et de son bien-être. Rencontre avec trois médecins sur le terrain.

Le centre de commande de l'hôpital temporaire installé dans les halles caverneuses de Asia World Expo, un centre des congrès situé non loin de l'Aéroport de Hong Kong, a des airs de ruche affairée en cet aprèsmidi de février. Quelques médecins en blouse blanche discutent des patients du jour dans un coin de la grande pièce éclairée au néon. Des infirmières analysent des fichiers Excel détaillant l'état de santé de toutes les personnes hébergées ici. Et des gardes de sécurité scrutent des images de caméras de surveillance sur un écran géant, montrant des dizaines de rangées de lits séparés par des parois amovibles.

«Nous accueillons ici toutes les personnes qui ont été testées positives au Covid-19 mais qui ne présentent que des symptômes légers ou pas de symptômes du tout», détaille Larry Lee, le médecin en charge du centre. «Le critère pour les admettre, c'est qu'ils ne nécessitent pas d'intervention médicale.» L'hôpital temporaire peut héberger 900 patients. «Mais actuellement, il n'y en a que 80 ", précise le médecin de 48 ans, qui co-dirige normalement un hôpital en banlieue de Hong Kong.

Un centre de tri a été installé dans une autre aile du centre des congrès pour séparer les patients en cas préliminaires (un test positif) et confirmés (deux tests positifs). Une fois l'infection confirmée, les malades sont transportés en navette jusqu'à l'hôpital temporaire. Ils doivent y rester jusqu'à ce que le virus ne soit plus détectable dans leur salive ou qu'un test sanguin démontre la présence d'anticorps. Durant leur séjour, 
d'une dizaine de jours en moyenne, ils n'ont pas le droit de quitter le périmètre de l'hôpital.

\section{Stratégie rodée depuis 2003}

«Nous avons commencé à envisager un tel centre en mars dernier, lorsque le nombre de cas a explosé à Singapour, un petit territoire très peuplé qui présente les mêmes caractéristiques que Hong Kong», raconte Larry Lee. «Sachant que près de $70 \%$ des cas sont légers ou asymptomatiques, il nous a semblé crucial de décharger les hôpitaux - qui ne comptent que 1500 lits d'isolement - en hébergeant ces personnes dans un établissement temporaire situé loin du centre-ville.» L'expérience du SARS en 2003, durant laquelle il n'était encore qu'un jeune médecin urgentiste, a en effet fait prendre conscience au corps médical local que pour garder un taux de mortalité bas, il fallait à tout prix éviter que le système hospitalier ne s'effondre, précise-t-il.

Mais l'émergence d'une seconde vague durant l'été 2020 a pris tout le monde de court. "Au final, nous avons dû monter l'hôpital en moins de 72 heures», glisse son responsable. Fin février, il a été assorti d'une autre structure - hébergée dans une série de bâtiments en préfabriqué - capable d'accueillir les cas intermédiaires, soit ceux nécessitant un traitement antiviral ou un apport en oxygène de faible intensité.

Ces structures temporaires, qui ont permis à Hong Kong d'isoler chaque cas de Covid-19 détecté depuis le début de la pandémie, ne représentent que l'une des

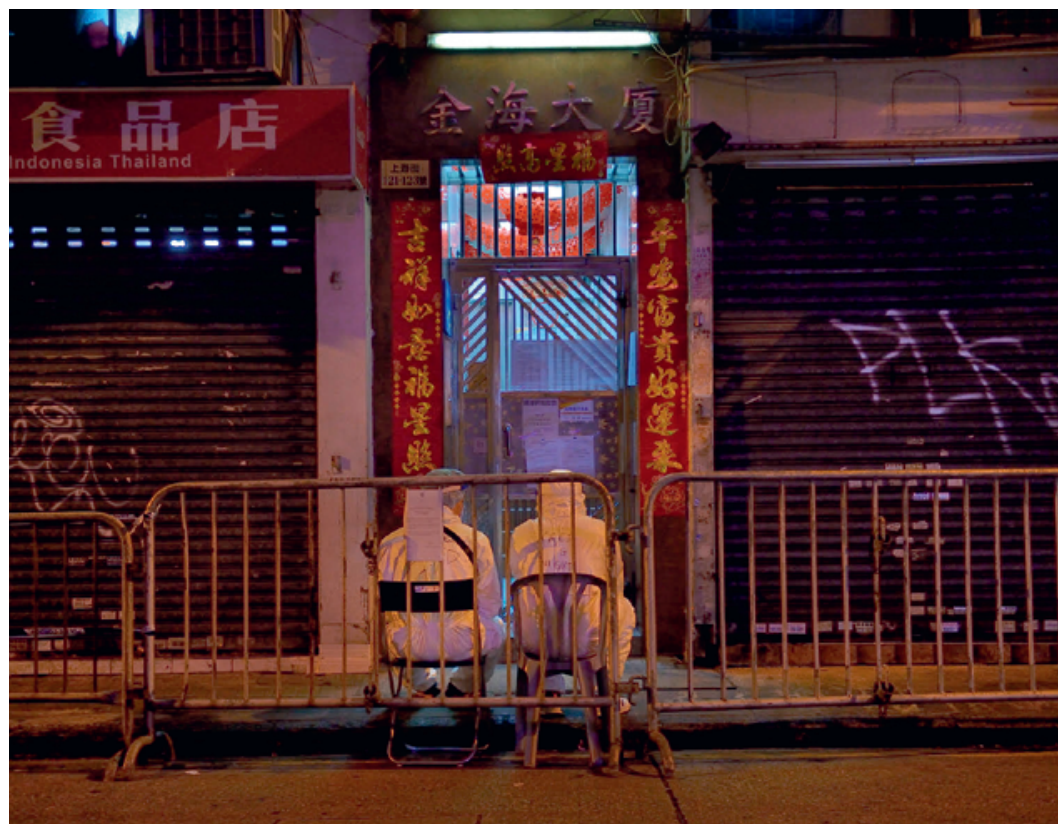

En janvier et février, le gouvernement a imposé des confinements forcés à 26 reprises pour tester tous les résidents d'un quartier ou d'un immeuble. (c) Marc Progin

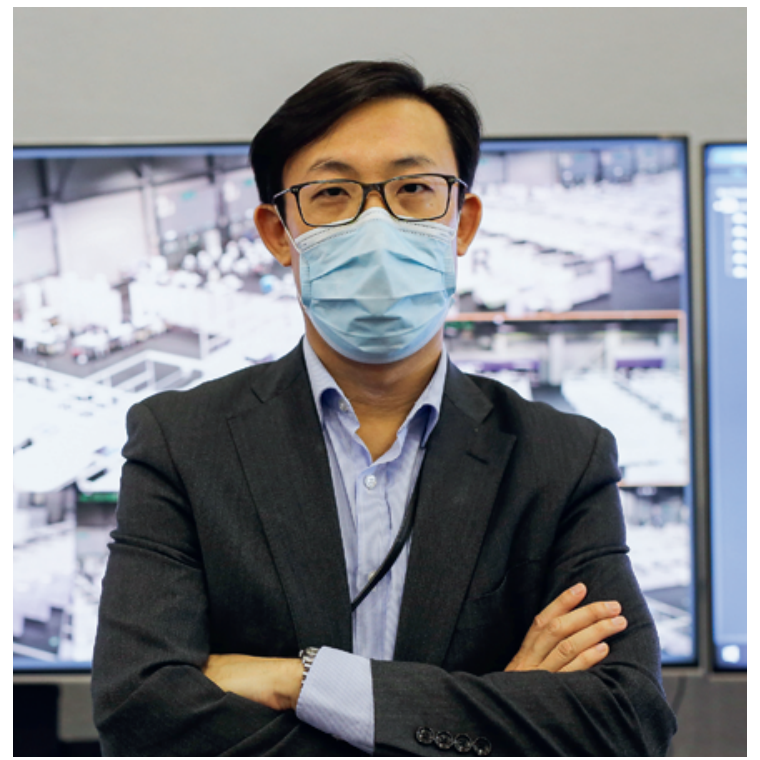

Larry Lee dirige I'hôpital temporaire installé à Asia World Expo. II a été mis sur pied en 72 heures lorsque les cas de Covid-19 ont commencé à grimper l'été dernier. (c) Julie Zaugg

facettes d'une stratégie bien rodée mise en place à l'issue de la pandémie de SARS. Cette stratégie a permis à la cité portuaire d'éviter un confinement strict et de garder ses restaurants, ses magasins et même ses parcs d'attraction ouverts durant une bonne partie de la pandémie. Hong Kong n'a enregistré que 10897 cas de Covid-19 et 197 décès pour une population similaire à celle de la Suisse.

\section{La police fait du porte-à-porte}

La mesure la plus spectaculaire reste la mise sous cloche de quartiers entiers durant 48 heures, pour tester tout le monde. En janvier, 3000 policiers ont déployé un cordon sanitaire autour du quartier de Yau Tsim Mong, l'un des plus densément peuplés de la planète, et ont fait du porte-à-porte pour récolter des échantillons auprès de 7000 résidents. Ces derniers avaient l'interdiction formelle de quitter leur domicile durant toute la durée de l'opération. Annoncés quelques minutes à peine avant leur entrée en vigueur, ces confinements forcés ont suscité pas mal de grogne au sein de la population. Lors de l'une de ces opérations, plusieurs personnes se sont par exemple retrouvées coincées dans un salon de coiffure durant une bonne partie de la nuit, dont une fillette de 11 ans.

«Le rapport entre leur coût et leur efficacité laisse en outre à désirer», complète Chi Chiu Leung, un spécialiste des maladies respiratoires, qui rappelle que seul une vingtaine de cas ont été repérés au cours des 26 interventions menées en janvier et février. 
Comme la Chine continentale, Hong Kong mise aussi sur les tests nucléiques à grande échelle. Des stations sanitaires ont été installées aux quatre coins de la ville pour permettre aux gens de se faire tester gratuitement. Pour certaines catégories de la population, le test est obligatoire et ne pas s'y soumettre coûte 25000 HKD (2900 francs) et peut être passible de six mois en prison. "Cela concerne les personnes présentant des symptômes ou résidant dans un immeuble où un cluster de cas a été identifié, ainsi que certaines professions à risque comme les chauffeurs de taxi, les serveurs, les employés de fitness et les esthéticiennes, qui doivent se faire tester toutes les deux semaines", détaille Keiji Fukuda, le directeur de l'école de santé publique de l'Université de Hong Kong, qui a autrefois œuvré pour l'OMS à Genève.

\section{Des traces de virus dans les égouts}

Un projet pilote initié par l'Université de Hong Kong en octobre dernier a en outre permis d'identifier deux immeubles abritant des cas de Covid-19 en prélevant des échantillons dans les égouts de la ville. Tous les résidents ont par la suite été testés. "Cette méthode est utilisée depuis des années pour repérer les cas de polio", précise Keiji Fukuda.

Ces tests exhaustifs ont pour but de repérer les chaînes de transmissions cachées dans la communauté, afin de faire baisser le taux de reproduction du virus, soit le nombre de personnes que chaque nouveau patient infecte. Ils sont assortis d'un dispositif élaboré de traçages de contacts. Hébergés dans un terminal normalement utilisé par les navires de croisière, quelque 200 policiers, douaniers et pompiers retracent les allées et venues de chaque cas positif au cours d'entretiens téléphoniques fouillés.

Lorsqu'un "contact proche» est identifié, soit quelqu'un ayant passé plus de 15 minutes avec le malade sans porter de masque, celui-ci est isolé durant 14 jours dans l'un des centres de quarantaine du gouvernement. Ils sont près de 30000 à avoir subi ce sort depuis le début de la pandémie. Plus récemment, le gouvernement a introduit une application appelée Leave Home Safe qui enregistre sur le téléphone de l'usager tous les lieux qu'il a fréquentés durant les 14 derniers jours, grâce à un système de codes QR installés à l'entrée des restaurants, des bureaux et des magasins.

\section{Coincés de longs mois à l'étranger}

La fermeture hermétique des frontières du petit territoire lui a également permis d'éviter une hausse vertigineuse des cas, comme en Europe de l'ouest, selon

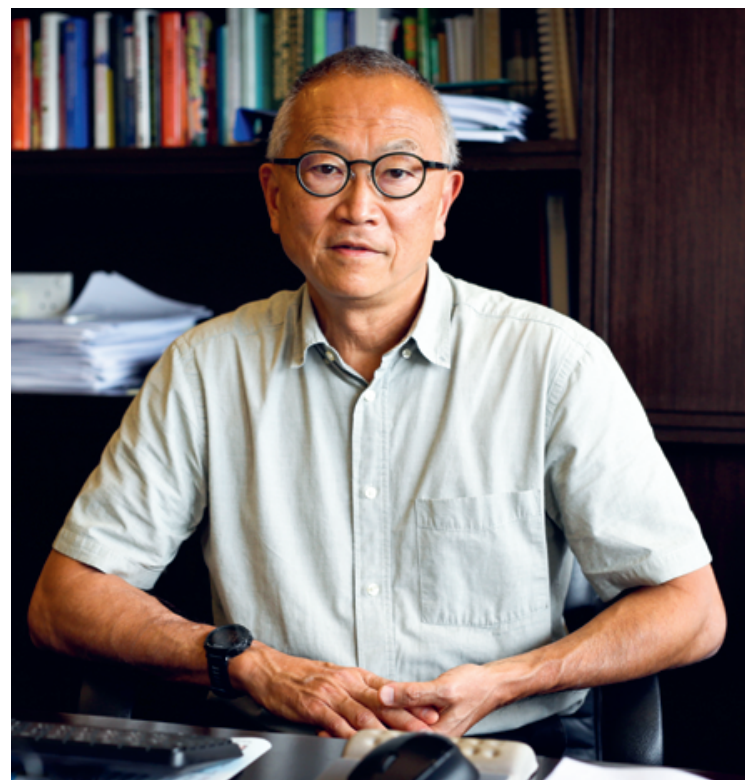

Directeur de l'école de santé publique de I’Université de Hong Kong, Keiji Fukuda conseille le gouvernement depuis le début de la pandémie. (C) Julie Zaugg

Keiji Fukuda. «Dès l'annonce des premiers cas à Wuhan, le gouvernement a fermé la frontière avec la Chine», se remémore-t-il. Aujourd'hui, seuls les résidents ont le droit de passer la frontière et ils doivent se soumettre à trois semaines de quarantaine dans l'un des 36 hôtels désignés par le gouvernement.

Keiji Fukuda reconnaît toutefois que la mesure fait peser un poids considérable sur la population et l'économie, très dépendante du tourisme. "De nombreux commerçants sont à l'article de la mort et des résidents se sont retrouvés coincés à l'étranger ou séparés de leur famille durant de longs mois», glisse-t-il. Les médias foisonnent de récits apocalyptiques de personnes en quarantaine: il y a celui d'une fille de huit ans enlevée à sa mère et placée en isolement deux semaines dans un hôpital après un test positif à son arrivée à l'Aéroport de Hong Kong ou celui de ce petit de cinq ans attaché à un lit d'hôpital, vêtu de couches sales, dont les parents étaient confinés dans un centre de quarantaine.

Malgré ces désagréments, la population soutient majoritairement l'action du gouvernement. «La clef du succès hongkongais réside dans l'adhésion des citoyens aux mesures décrétées par les autorités», estime Chi Chiu Leung, qui a publié un papier sur ce sujet dans The Lancet. "Dès le mois de janvier 2020, tout le monde a chaussé un masque et a commencé à se désinfecter les mains. Cela a stoppé tout net la propagation du virus. Ce facteur est présent dans tous les pays qui sont parvenus à se défaire du virus, que ce soit la Nouvelle-Zélande, Taïwan ou la Chine», rappelle-t-il. 